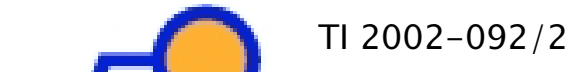 \\ Tinbergen Institute Discussion Paper \\ The Comovement between Real Activity and Prices in the G7
}

\author{
Wouter J. den Haan',2 \\ Steven W. Sumner
}

1 University of California at San Diego, USA,

2 CEPR, NBER, Tinbergen Institute. 
Tinbergen Institute

The Tinbergen Institute is the institute for economic research of the Erasmus Universiteit Rotterdam, Universiteit van Amsterdam and

Vrije Universiteit Amsterdam.

Tinbergen I nstitute Amsterdam

Keizersgracht 482

1017 EG Amsterdam

The Netherlands

Tel.: +31.(0)20.5513500

Fax: $\quad+31 .(0) 20.5513555$

Tinbergen Institute Rotterdam

Burg. Oudlaan 50

3062 PA Rotterdam

The Netherlands

Tel.: $\quad+31 .(0) 10.4088900$

Fax: $\quad+31 .(0) 10.4089031$

Most TI discussion papers can be downloaded at

http://www.tinbergen.nl 


\title{
THE COMOVEMENT BETWEEN REAL ACTIVITY AND PRICES IN THE G7
}

\author{
WOUTER J. DEN HAAN \\ University of California at San Diego, CEPR \& NBER \\ and \\ STEVEN W. SUMNER \\ University of California at San Diego
}

First Version: March 2001

This Version: August 2002

\begin{abstract}
In this paper, we study the short-run and long-run comovement between prices and real activity in the G7 countries during the postwar period using VAR forecast errors and frequency domain filters. We find several patterns of the correlation coefficients that are robust across countries and time periods; typically, the correlation coefficients at long-run horizons are significantly negative and the correlation coefficients at short-run horizons are substantially higher. Additionally, there is evidence of positive correlation at short-run forecast horizons for some countries.
\end{abstract}

We are grateful to Marianne Baxter, Timothy Cogley, Marjorie Flavin, Clive Granger, Jim Hamilton, Robert King, Valerie Ramey, Bharat Trehan, Harold Uhlig, and three anonymous referees for useful comments. 


\section{Introduction}

This paper examines the comovement between prices and output for the G7 countries (Canada, France, Germany, Italy, Japan, the U.K., and the U.S.) during the postwar period. The comovement between prices and output is described using the correlation coefficients of VAR forecast errors at different forecast horizons as proposed in Den Haan (2000). This procedure has two important advantages over traditional statistics used in the literature. First, the procedure considers a full set of statistics to characterize the dynamics in an efficient manner. As pointed out by Hansen and Heckman (1996) the observed dynamics of economic variables provide important identifying information to evaluate dynamic macroeconomic models. Second, the statistics are intuitive and easy to interpret. The correlation of detrended series is much harder to interpret since one has to understand the dynamics of the trend.

These advantages are illustrated in Den Haan (2000) for the comovement between prices and output. Through the use of this procedure, Den Haan is able to question a class of theoretical models believed to be consistent with empirical findings based on traditional statistics. Cooley and Ohanian (1991) show that the correlation between prices and real activity filtered with the HP filter of Hodrick and Prescott (1997) is negative in the postwar period, which might seem inconsistent with a model in which demand shocks play a dominant role. However, this empirical finding can be consistent with models of sticky prices that only have demand shocks. In this type of model, just after a positive demand shock the price level has not moved very much but the HP-trend level has already increased considerably — implying that the detrended price observation is negative. This together with a positive detrended output observation produces a negative correlation. ${ }^{1}$ Using VAR forecast errors for prices and output, Den Haan (2000) finds that the correlation coefficients become negative when the forecast horizon increases; typically at forecast horizons between one and two years. More importantly, the observed negative correlation between prices and output VAR forecast errors are shown to be not consistent with a sticky price model with only demand shocks.

Given that these correlation coefficients have important information allowing one to distinguish between different models, the question arises whether the same results are

\footnotetext{
1 See Ball and Mankiw (1994), Chadha and Prasad (1993), and Judd and Trehan (1995).
} 
true for different time periods and different countries. A priori, there is no reason to believe that the observed patterns are the same for different countries given that there are important differences in, for example, institutions and monetary policy. Similarly, the comovement between HP-filtered prices and output is not stable across time. ${ }^{2}$ It might, therefore, also be possible that during the 1980's and 1990's, during which inflation was substantially lower and less volatile than in the 1970's, the correlation between prices and output changed. In this paper, however, we show that the comovement between prices and output is robust across the G7 countries and that the comovement pattern during the period from 1980 to 2001 is for most countries similar to the pattern for the period from 1960 to 2001. In particular, we find that, the "long-run" correlations between prices and output are significantly negative and that the correlations become less negative when the forecast horizon shortens. Additionally, there is evidence of positive correlation at "short-run" forecast horizons for some countries. ${ }^{3}$

Using the frequency-domain filters proposed in Baxter and King (1999) we show that the correlation pattern between prices and output detrended with high-pass filters is also similar across countries. The paper is organized as follows. Section 2 reports some traditional measures of comovement and Section 3 presents the correlation coefficients of the VAR forecast errors. Section 4 discusses the correlation coefficients when frequencydomain filters are used. The last section compares the results of the different methods.

\section{Measuring comovement with traditional statistics}

We report in Table 1 the correlation of output growth and inflation at different leads and lags and in Table 2 the correlation of HP-filtered output and prices. For each country we report the results for the full sample that comprises the last four decades and the shorter sample that only comprises the last two decades. For all seven countries we report results for monthly industrial production and the consumer price index and for the

\footnotetext{
${ }^{2}$ Cooley and Ohanian (1991) show that in contrast to the postwar period, HP-detrended prices and output are positively correlated in the U.S.. Ravn and Sola (1995) show that the procyclicality of inflation in the U.S. is a phenomenon mainly associated with the later part of the inter-war period and the second world war.

3 At what forecast horizon the correlation turns negative depends to some extent on the data set, but roughly speaking "long-run" corresponds with forecast horizons bigger than two years and "short-run" with forecast horizons less than one year.
} 
U.K. and the U.S. we also report the results for quarterly GDP and its deflator. ${ }^{4}$ We also report average inflation rates and standard deviations to indicate that during the last two decades the series became less volatile and that average inflation rates declined. ${ }^{5}$

The correlation coefficients between monthly inflation and output growth rates are typically negative but also small and insignificant; so it is hard to discover any interesting patterns. The correlation coefficients for quarterly data are also negative but substantially bigger in absolute value. Also note that in the U.K. these correlation coefficients are substantially more negative in the shorter sample. The correlation coefficients between HP-filtered output and inflation are substantially more negative and significant. Note that for all countries filtered output is leading filtered prices. When we compare the two samples, we observe that for the monthly Japanese and U.S. series the correlation has become less negative during the last two decades, while for the monthly Canadian and the quarterly U.K. series the correlation has become more negative.

Table 1: Correlation of output growth and inflation

\begin{tabular}{|c|c|c|c|c|c|c|c|c|}
\hline & & \multicolumn{2}{|c|}{$\Delta p_{t}$} & \multicolumn{5}{|c|}{$\operatorname{COR}\left(\Delta y_{t}, \Delta p_{t+\mathrm{k}}\right)$} \\
\hline & & average & st.dev & -2 & -1 & 0 & 1 & 2 \\
\hline \multicolumn{9}{|l|}{ Monthly Data } \\
\hline \multirow[t]{2}{*}{ U.S. } & '61-'01 & $4.35 \% *$ & $4.14 \% *$ & $-0.20 *$ & $-0.14^{*}$ & $-0.12 *$ & -0.10 & -0.05 \\
\hline & '80-'01 & $3.43 \% *$ & $3.66 \% *$ & $-0.24^{*}$ & $-0.16^{*}$ & -0.03 & 0.03 & 0.05 \\
\hline \multirow[t]{2}{*}{ U.K. } & '61-'01 & $6.38 \% *$ & $8.22 \% *$ & -0.03 & -0.05 & -0.05 & 0.02 & -0.01 \\
\hline & '80-'01 & $4.32 \% *$ & $6.53 \% *$ & -0.04 & -0.11 & -0.04 & 0.01 & -0.00 \\
\hline \multirow[t]{2}{*}{ Japan } & '61-'01 & $4.10 \% *$ & $8.81 \% *$ & 0.00 & 0.02 & 0.00 & 0.05 & 0.05 \\
\hline & '80-'01 & $1.19 \% *$ & $5.90 \% *$ & -0.04 & -0.01 & 0.02 & -0.03 & 0.10 \\
\hline \multirow[t]{2}{*}{ Italy } & '61-'01 & $7.32 \% *$ & $7.45 \% *$ & 0.00 & 0.01 & -0.05 & 0.04 & -0.05 \\
\hline & '80-'01 & $5.98 \% *$ & $6.57 \% *$ & -0.01 & -0.00 & -0.09 & -0.04 & -0.07 \\
\hline \multirow[t]{2}{*}{ Germany } & '61-'01 & $3.10 \% *$ & $3.98 \% *$ & -0.04 & -0.04 & -0.08 & -0.06 & 0.01 \\
\hline & '80-'01 & $2.40 \% *$ & $3.63 \% *$ & -0.03 & -0.08 & -0.10 & -0.06 & 0.02 \\
\hline \multirow[t]{2}{*}{ France } & '61-'01 & $5.12 \% *$ & $4.94 \% *$ & -0.05 & -0.01 & -0.02 & 0.03 & 0.01 \\
\hline & '80-'01 & $3.59 \% *$ & $4.46 \% *$ & -0.05 & -0.06 & -0.11 & -0.01 & -0.03 \\
\hline \multirow[t]{2}{*}{ Canada } & '62-'01 & $4.57 \% *$ & $5.05 \% *$ & -0.10 & -0.07 & -0.15 & -0.08 & 0.01 \\
\hline & '80-'01 & $4.53 \% *$ & $4.72 \% *$ & -0.10 & -0.14 & -0.13 & -0.11 & -0.02 \\
\hline \multicolumn{9}{|l|}{ Ouarterly } \\
\hline \multirow[t]{2}{*}{ U.S. } & '61-'01 & $3.91 \% *$ & $2.49 \% *$ & $-0.30 *$ & $-0.30 *$ & $-0.28 *$ & $-0.25 *$ & $-0.22 *$ \\
\hline & '80-'01 & $3.17 \% *$ & $2.07 \% *$ & $-0.26^{*}$ & $-0.33^{*}$ & $-0.25^{*}$ & $-0.21 *$ & $-0.31 *$ \\
\hline \multirow[t]{2}{*}{ U.K. } & '61-'01 & $6.51 \% *$ & $5.77 \% *$ & $-0.17 *$ & $-0.26^{*}$ & $-0.28 *$ & -0.15 & $-0.14^{*}$ \\
\hline & '80-'01 & $3.54 \% *$ & $3.78 \% *$ & $-0.31 *$ & $-0.50 *$ & $-0.54^{*}$ & $-0.31 *$ & $-0.26^{*}$ \\
\hline
\end{tabular}

Note: An asterisk indicates a coefficient is significantly different from zero using a $5 \%$ one-side test based on the VARHAC procedure described in Den Haan and Levin (1997). Growth rates are expressed on an annual basis.

\footnotetext{
${ }^{4}$ Data sources are given in the appendix.

${ }^{5}$ Ravn and Sola (1995) document for Germany, Japan, the U.K. and the U.S. that the period after 1980 was a "low-inflation" regime, although some short episodes prior to 1980 are also characterized as such.
} 
Table 2: Correlations of HP-filtered output and prices

\begin{tabular}{|c|c|c|c|c|c|c|c|c|}
\hline & & \multicolumn{2}{|c|}{ st.dev } & \multicolumn{5}{|c|}{$\operatorname{COR}\left(y_{t}^{h p}, p_{t+k}^{h p}\right)$} \\
\hline & & $p_{t}^{h p}$ & $y_{t}^{h p}$ & -2 & -1 & 0 & 1 & 2 \\
\hline \multicolumn{9}{|l|}{ Monthly Data } \\
\hline \multirow[t]{2}{*}{ U.S. } & '61-'01 & $1.35 \% *$ & $3.19 \% *$ & $-0.62 *$ & $-0.57 *$ & $-0.51 *$ & $-0.45^{*}$ & $-0.40 *$ \\
\hline & '80-'01 & $1.21 \% *$ & $2.51 \% *$ & $-0.39 *$ & $-0.33^{*}$ & -0.25 & -0.20 & -0.15 \\
\hline \multirow[t]{2}{*}{ U.K. } & '61-'01 & $2.03 \% *$ & $2.73 \% *$ & $-0.53 *$ & $-0.51 *$ & $-0.49 *$ & $-0.47^{*}$ & $-0.45 *$ \\
\hline & '80-'01 & $1.61 \% *$ & $2.15 \% *$ & $-0.54 *$ & $-0.49 *$ & $-0.43^{*}$ & $-0.39 *$ & $-0.36 *$ \\
\hline \multirow[t]{2}{*}{ Japan } & '61-'01 & $1.89 \% *$ & $4.04 \% *$ & $-0.46^{*}$ & $-0.41 *$ & $-0.35^{*}$ & $-0.30 *$ & $-0.25 *$ \\
\hline & '80-'01 & $0.85 \% *$ & $3.34 \% *$ & -0.11 & -0.07 & -0.02 & 0.04 & 0.10 \\
\hline \multirow[t]{2}{*}{ Italy } & '61-’01 & $1.74 \% *$ & $3.56 \% *$ & $-0.34 *$ & $-0.29 *$ & $-0.24^{*}$ & -0.18 & -0.14 \\
\hline & '80-'01 & $1.11 \% *$ & $2.82 \% *$ & $-0.39 *$ & $-0.37 *$ & $-0.35^{*}$ & $-0.33^{*}$ & $-0.31 *$ \\
\hline \multirow[t]{2}{*}{ Germany } & '61-'01 & $1.09 \% *$ & $3.17 \% *$ & $-0.42 *$ & $-0.41 *$ & $-0.38 *$ & $-0.35^{*}$ & $-0.31 *$ \\
\hline & '80-'01 & $1.03 \% *$ & $2.80 \% *$ & $-0.35^{*}$ & -0.34 & -0.33 & -0.30 & -0.27 \\
\hline \multirow[t]{2}{*}{ France } & '61-'01 & $1.15 \% *$ & $3.12 \% *$ & $-0.27 *$ & $-0.24 *$ & $-0.22 *$ & $-0.19 *$ & $-0.17 *$ \\
\hline & '80-'01 & $0.92 \% *$ & $1.74 \% *$ & $-0.22 *$ & $-0.21 *$ & $-0.20 *$ & -0.17 & -0.16 \\
\hline \multirow[t]{2}{*}{ Canada } & '62-'01 & $1.26 \% *$ & $3.42 \% *$ & $-0.62 *$ & $-0.59 *$ & $-0.56^{*}$ & $-0.52 *$ & $-0.48 *$ \\
\hline & '80-'01 & $1.22 \% *$ & $3.47 \% *$ & $-0.72 *$ & $-0.70 *$ & $-0.68 *$ & $-0.66^{*}$ & $-0.63 *$ \\
\hline \multicolumn{9}{|l|}{ Quarterly } \\
\hline \multirow[t]{2}{*}{ U.S. } & '61-'01 & $0.84 \% *$ & $1.58 \% *$ & $-0.75^{*}$ & $-0.74 *$ & $-0.68 *$ & $-0.58^{*}$ & $-0.44 *$ \\
\hline & '80-'01 & $0.75 \% *$ & $1.37 \% *$ & $-0.68 *$ & $-0.61 *$ & $-0.51 *$ & $-0.41 *$ & $-0.31 *$ \\
\hline \multirow[t]{2}{*}{ U.K. } & '61-'01 & $2.04 \% *$ & $1.52 \% *$ & $-0.55^{*}$ & $-0.61 *$ & $-0.59 *$ & $-0.50 *$ & $-0.39 *$ \\
\hline & '80-'01 & $1.55 \% *$ & $1.32 \% *$ & $-0.72 *$ & $-0.67 *$ & $-0.55^{*}$ & $-0.39 *$ & $-0.25 *$ \\
\hline
\end{tabular}

Note: An asterisk indicates a coefficient is significantly different from zero using a $5 \%$ one-side test based on the VARHAC procedure described in Den Haan and Levin (1997). Growth rates are expressed on an annual basis. For quarterly data we follow tradition and set the smoothing parameter of the HP filter equal to 1600 . For monthly data we follow Ravn and Uhlig (2002) and set it equal to 129600.

\section{Measuring comovement with VAR forecast errors}

In Section 3.1, we give the results for the monthly series and in Section 3.2 for the quarterly series. The data sources are given in the appendix.

\subsection{Monthly VAR forecast errors}

Consider $X_{t}$, the $2 \times 1$ vector containing the log price level, $P_{t}$, and the log of output, $Y_{t}$. The estimated VAR can then be written as:

$$
X_{t}=a_{0}+a_{1} t+a_{2} t^{2}+\sum_{l=1}^{12} A_{l} X_{t-l}+u_{t}
$$

where the $A_{l}$ 's are $2 \times 2$ matrices of regression coefficients; $a_{0}, a_{1}$, and $a_{2}$ are $2 \times 1$ vectors of constants; $u_{t}$ is a $2 \times 1$ vector of innovations. The benchmark specification includes one year of lags. Let $P_{t+K, t}^{u e}$ and $Y_{t+K, t}^{u e}$ denote the $K$-period ahead forecast error of the variables $Y_{t}$ and $P_{t}$, respectively. Given estimates of the regression coefficients and the covariance matrix of $u_{t}$, it is relatively straightforward to calculate the implied covariance and 
correlation coefficient between the $K$-period ahead forecast errors of output and the price level. ${ }^{6}$ The results reported in this paper are based on the VAR specification given in (3.1), but we also calculated the results for the VAR specification that was selected by the Akaike Information Criterion (AIC) and for the VAR specification that imposed unit roots. Those results are virtually identical to the ones presented here and are not included in the paper. ${ }^{7}$

Panels A through G in Figure 1 report the results based on the VAR estimated over the period from February 1961 to December 2001 and over the period from January 1980 to December $2001 .^{8}$ As documented in the figure, for the sample period from 1961 to 2001 the correlation coefficients of all G7 countries become significantly negative at the $5 \%$ level as the forecast horizon increases. Moreover, the short-term correlation coefficients are substantially higher for all countries. These measures of comovement reveal characteristics of the data that were not brought to light by the traditional measures discussed in Section 2. In particular, for the full French, Italian, and U.S. sample, significant positive correlation coefficients are found at forecast horizons of less than one year.

Figure 1: Correlation coefficients of VAR forecast errors using monthly data

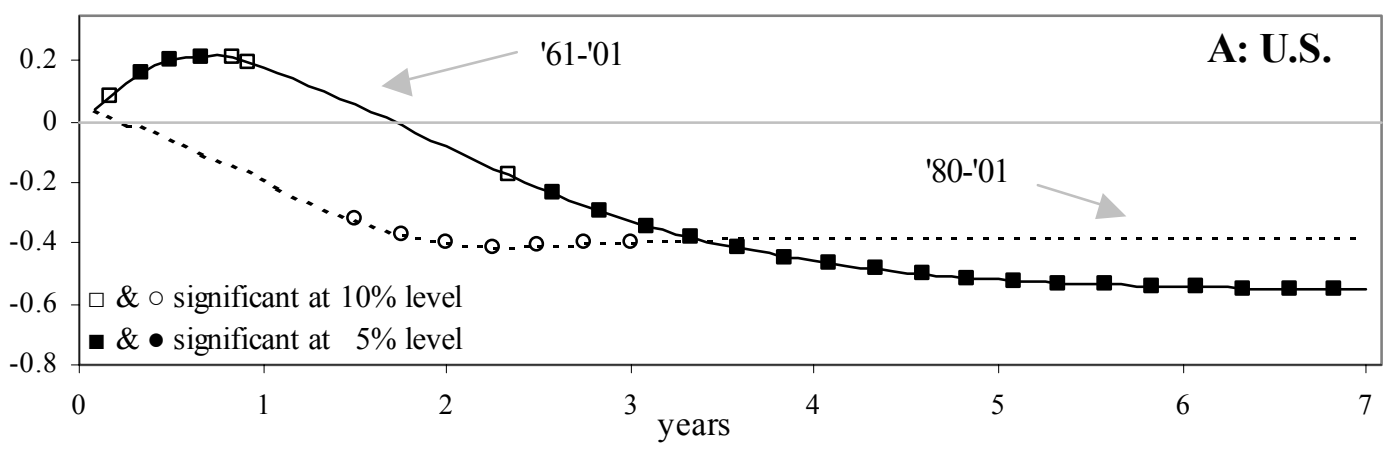

\footnotetext{
${ }^{6}$ See Den Haan and Sumner (2001) for a detailed discussion. This paper also documents that using the correlation coefficients implied by the estimated VAR instead of estimates based on the actual forecast errors as in Den Haan (2000) results in estimates for the correlation coefficients with much smaller standard errors.

${ }^{7}$ The results are summarized in a note that is available at http://weber.ucsd.edu/ $\sim$ wdenhaan. The note also documents that the results are robust to the inclusion of the real wage rate and to using the producer price index instead of the consumer price index. Also, in Den Haan (2000) it is shown that the results do not change when the federal funds rate, non-borrowed reserves, and total reserves are added to the VAR.

${ }^{8}$ For Canada the estimation for the full sample is over the period from February 1962 to December 2001.
} 

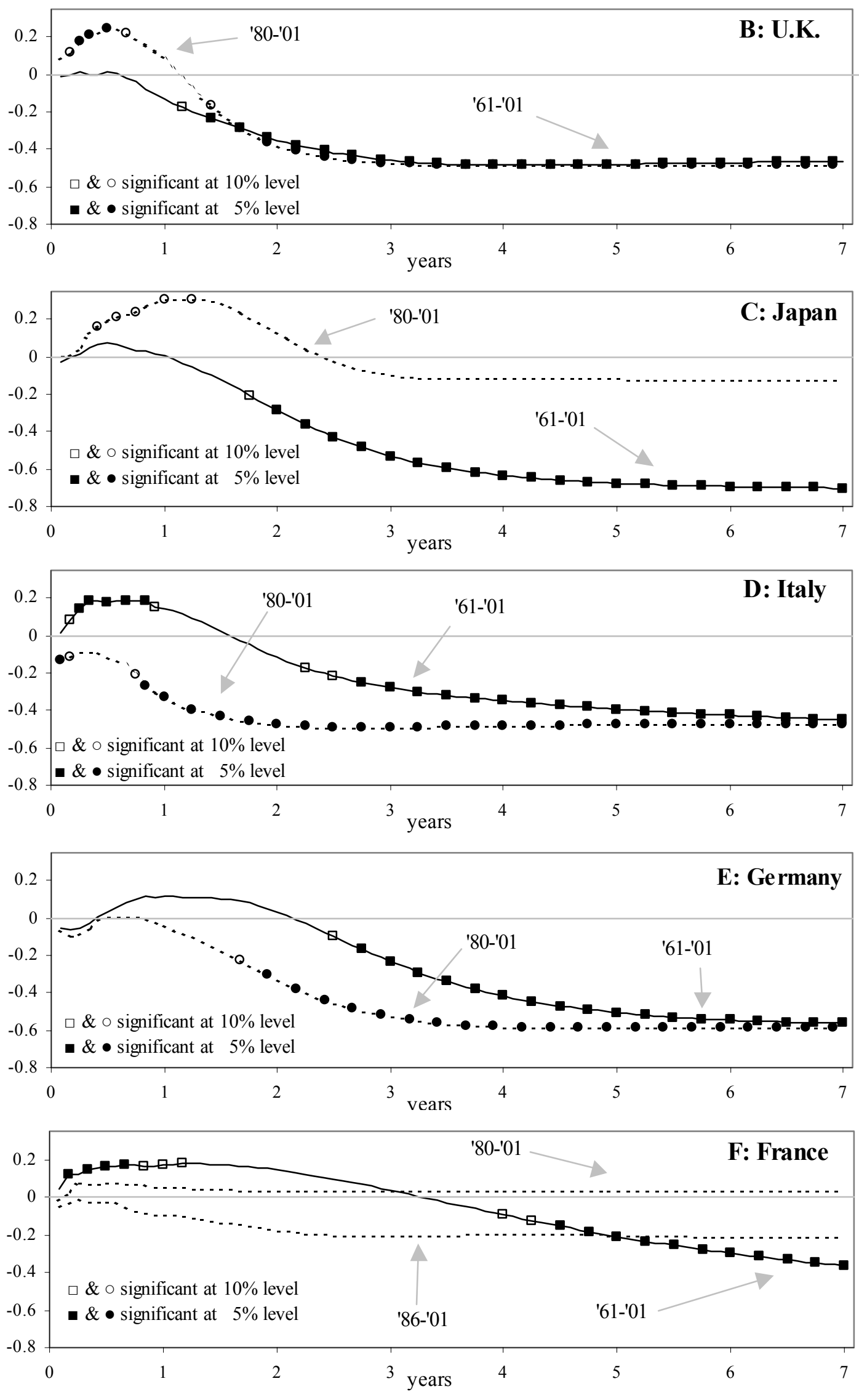


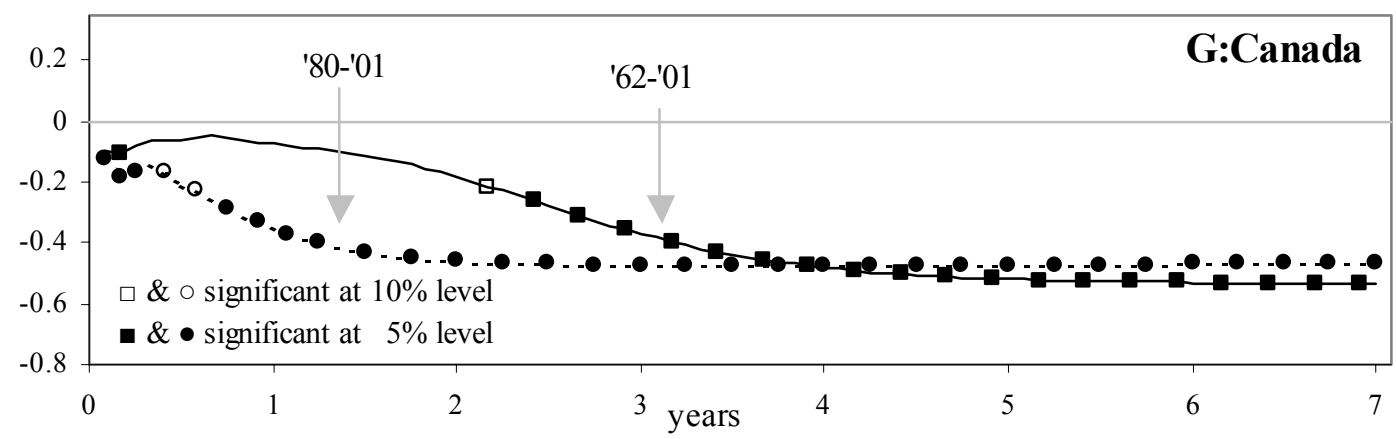

Note: These panels plot the correlation coefficients of the $K$-period ahead forecast errors of the CPI and industrial production. Significance levels are based on Monte-Carlo confidence intervals.

Except for France, we find that the general pattern of comovement is very similar when the VAR is estimated over the period from 1980 to 2001. The significance levels are somewhat less impressive but this is not surprising given that the sample is much shorter. Nevertheless we find significant negative correlation coefficients for five of the seven countries. In four countries, Canada, Germany, Italy, and the U.S., the correlation coefficients seem to be more negative during the last two decades. In the UK short-run correlation coefficients are significantly positive in the shorter sample, whereas for the full sample these were only marginally above zero.

For the shorter French sample, no negative correlation coefficients are observed,and for the shorter Japanese sample the long-run correlation coefficients are much less negative than those observed for the full sample. Japan's recent experience of huge real activity swings and near zero inflation was, of course, very unusual. A visual inspection of the French inflation rate shows two distinct trends. Average inflation first decreased rapidly from double digit numbers to around two percent in 1986. After a small increase the inflation rate then steadily declined to near zero levels in 1998. Panel F in Figure 1 documents that when the VAR is estimated over the period from 1986 to 2001 then the coefficients are negative again.

The changes observed, when we limit the sample to the last two decades, sometimes do not even go in the same direction as the changes observed with the traditional statistics. For example, with the VAR forecast errors we observe some UK coefficients that become positive in the recent sample while the statistics in Section 2 
indicate a stronger negative relationship. For the U.S. we observe the opposite. In Section 5 we offer an explanation for these findings.

A disadvantage of correlation coefficients is that it is impossible to evaluate the quantitative importance of the observed numbers. For example, it is possible that the positive correlation coefficients observed for the U.S. at short forecast horizons are quantitatively not important because the variances at these horizons are small too. To compare the quantitative importance of the comovement statistics at the different forecast horizons it is better to use covariances. Moreover, these measures also have a straightforward relationship with impulse response functions. Without loss of generality suppose that there are $M$ structural shocks driving output and prices. In this case, Den Haan (2000) shows that

$$
\operatorname{COV}(K)=\sum_{k=1}^{K} \operatorname{COV}^{\Delta}(k) \text { and } \operatorname{COV}^{\Delta}(k)=\sum_{m=1}^{M} Y_{k}^{i m p, m} p_{k}^{i m p, m},
$$

where $Z_{k}^{i m p, m}$ is the $k$-th period impulse response of variable $Z$ to a one-standard deviation disturbance of the $m$-th shock. The covariance of the $K$-period ahead forecast errors is, thus, the accumulated product of the price and output impulses averaged across the different structural shocks. For any finite $K$ we can analyze the $\operatorname{COV}(K)$ by plotting the $\operatorname{COV}^{\Delta}(k)$ for values of $k$ between 1 and $K$. This is done in Figure 2 using the full U.S. sample. The graph shows that the absolute value of the positive covariances is small relative to those of the negative covariances.

Figure 2: The importance of different forecast horizons

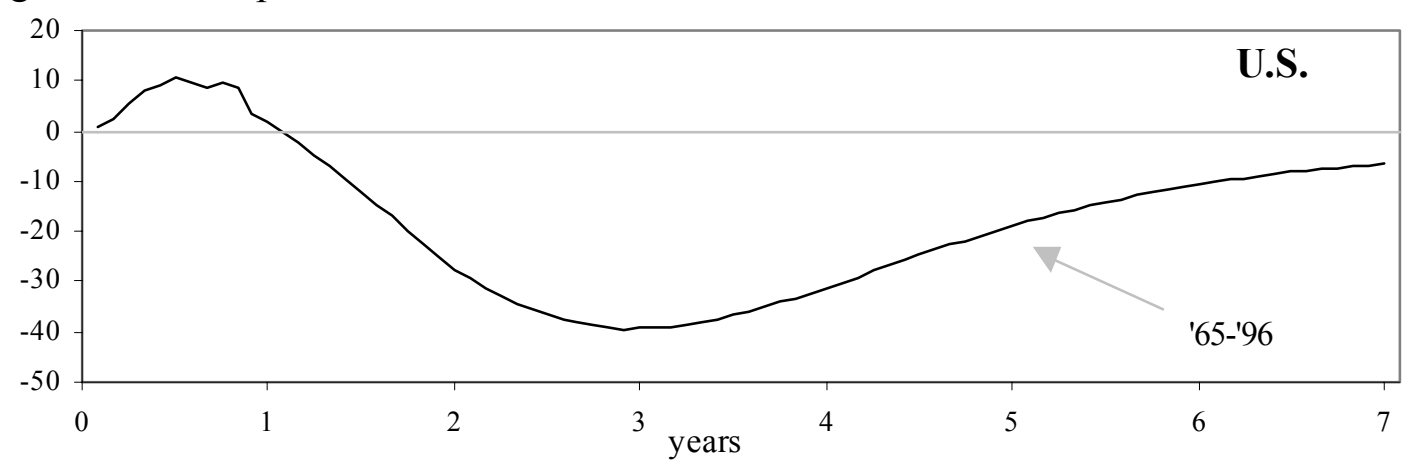

Note: This graph plots $\operatorname{COV}^{\Delta}(k)$ for different values of $k$. The value of $\operatorname{COV}(K)$ is equal to $\operatorname{COV}^{\Delta}(1)+$ $\operatorname{COV}^{\Delta}(2)+\cdots+\operatorname{COV}^{\Delta}(K)$. 


\subsection{Quarterly VAR forecast errors}

In this section we report the results for the comovement between quarterly GDP and its deflator for the U.S. and the U.K. These, are the only two countries for which quarterly GDP published by the OECD does not start after 1960. Again we estimate a bivariate VAR with one year of lags, a linear trend, and a quadratic trend.

Figure 3: Correlation coefficients of VAR forecast errors using quarterly data
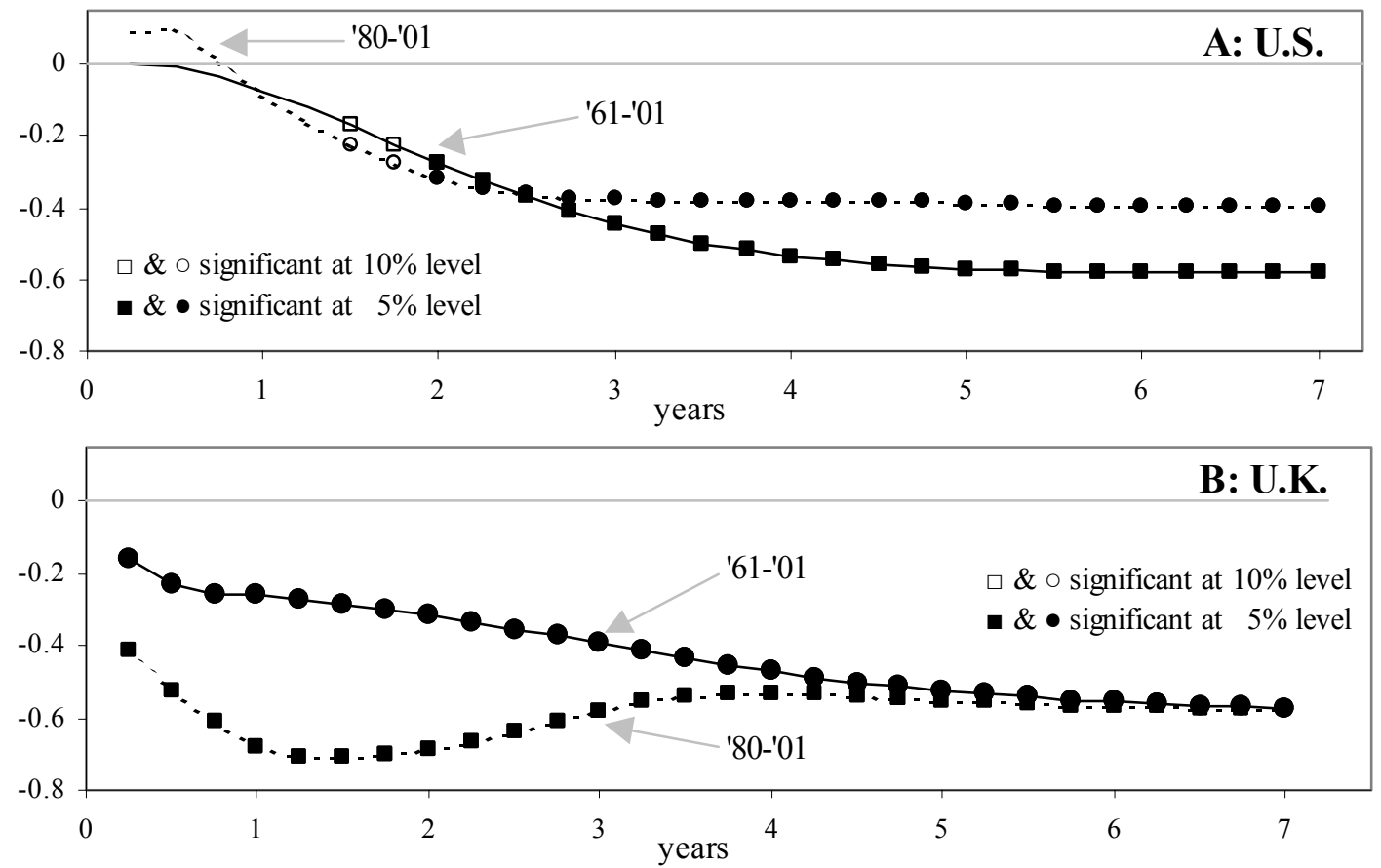

Note: These panels plot the correlation coefficients of the $K$-period ahead forecast errors of GDP and its deflator. Significance levels are based on Monte-Carlo confidence intervals.

As documented in Figure 3, significant negative coefficients are found for both countries. For the U.K. all coefficients are significantly negative in both sample periods. The positive correlation coefficients observed for the U.S. are small and insignificant. For the U.S. the results are also remarkably similar for the two sample periods, while for the U.K. correlation coefficients have become more negative at the shorter forecast horizons.

\section{Measuring comovement with high-pass filters}

In this section we investigate the comovement between filtered prices and output using high-pass filters to detrend the data. In Section 4.1, we justify using these filters for integrated series and in the other two sections we report the results. 


\subsection{Frequency-domain filters for integrated processes}

Band-pass filters decompose a time series into a trend and a residual component such that the spectrum of the residual is equal to the spectrum of the original for frequencies inside the band and zero for frequencies outside the band. An excellent description of the procedure can be found in Baxter and King (1999). In this section we show that this is true even when the series is integrated. According to the BeveridgeNelson decomposition, one can, under mild regularity conditions, write an I(1) process as the sum of a random walk, initial conditions, and a stationary process. ${ }^{9}$ Ignoring the initial conditions, we can write

$$
x_{t}=x_{t-1}+e_{t},
$$

where $e_{t}$ is a stationary process. Now consider the following process:

$$
x_{t}=\rho x_{t-1}+e_{t} .
$$

As long as $|\rho|<1$, the process defined in (4.2) is stationary and has a well-defined spectrum $S_{\rho}(\omega)=\left|1 /\left(1-\rho e^{-i \omega}\right)\right|^{2} S_{e}(\omega)$. Equation (4.1) can be written as:

$$
x_{t}=\lim _{\rho \rightarrow 1} \rho x_{t-1}+e_{t} .
$$

Equation (4.3) motivates the following definition of the spectrum of an I(1) process:

$$
S_{x}(\omega) \equiv \lim _{\rho \rightarrow 1} S_{\rho}(\omega)=\lim _{\rho \rightarrow 1}\left|\frac{1}{1-\rho e^{-i \omega}}\right|^{2} S_{e}(\omega) .
$$

Note that $S_{x}(\omega)$ is finite for all frequencies except possibly zero. The band-pass filter $A^{H}(L)$ is a symmetric filter with $A^{H}(1)=0$. Thus,

$$
A^{H}(L)=(1-L) \bar{A}^{H}(L) \text { with } \bar{A}^{H}(1)=0 .
$$

Let $x_{t}^{F, H}=A^{H}(L) x_{t}$. We have to show that even when $x_{t}$ is an I(1) process

$$
\begin{array}{ll}
S_{x^{F}}(\omega) \equiv \lim _{H \rightarrow \infty} S_{x^{F, H}}(\omega)=S_{x}(\omega) & \text { if } \omega_{1} \leq \omega \leq \omega_{2} \text { and } \\
S_{x^{F}}(\omega) \equiv \lim _{H \rightarrow \infty} S_{x^{F, H}}(\omega)=0 & \text { if } 0 \leq \omega<\omega_{1} \text { and } \omega_{2}<\omega \leq \pi,
\end{array}
$$

where $\omega_{1}$ and $\omega_{2}$ are the lower and upper bound of the band of included frequencies. The spectrum of $x_{t}^{F, H}$ is given by

$$
S_{x^{F, H}}(\omega)=\left|\frac{A^{H}\left(e^{-i \omega}\right)}{1-e^{-i \omega}}\right|^{2} S_{e}(\omega)=\lim _{\rho \rightarrow 1}\left|\frac{A^{H}\left(e^{-i \omega}\right)}{1-\rho e^{-i \omega}}\right|^{2} S_{e}(\omega)=\left|A^{H}\left(e^{-i \omega}\right)\right|^{2} S_{x}(\omega)
$$

\footnotetext{
${ }^{9}$ See, for example, Hamilton (1994).
} 
for $0<\omega \leq \pi$. Since $S_{x}(\omega)$ is well-defined for all values of $\omega$ larger than zero, Equation (4.7) directly implies the desired result described in (4.6) for $0<\omega \leq \pi$. It remains to be shown that $S_{x^{F, H}}$ is equal to zero when $\omega$ is equal to zero. From (4.5) we have that $S_{x^{F, H}}(0)$ is equal to zero for all $H$, which implies that

$$
S_{x^{F}}(0) \equiv \lim _{H \rightarrow \infty} S_{x^{F, H}}(0)=\lim _{H \rightarrow \infty} 0=0
$$

and completes the assertion. See Den Haan and Sumner (2001) for a detailed discussion.

\subsection{High-pass filters and monthly data}

Panels A through G in Figure 4 report the correlation between the filtered CPI and industrial production using high-pass filters that isolate that part of the series associated with frequencies corresponding to a period less than the indicated value on the $x$-axis.

Figure 4: Correlation coefficients of filtered monthly data
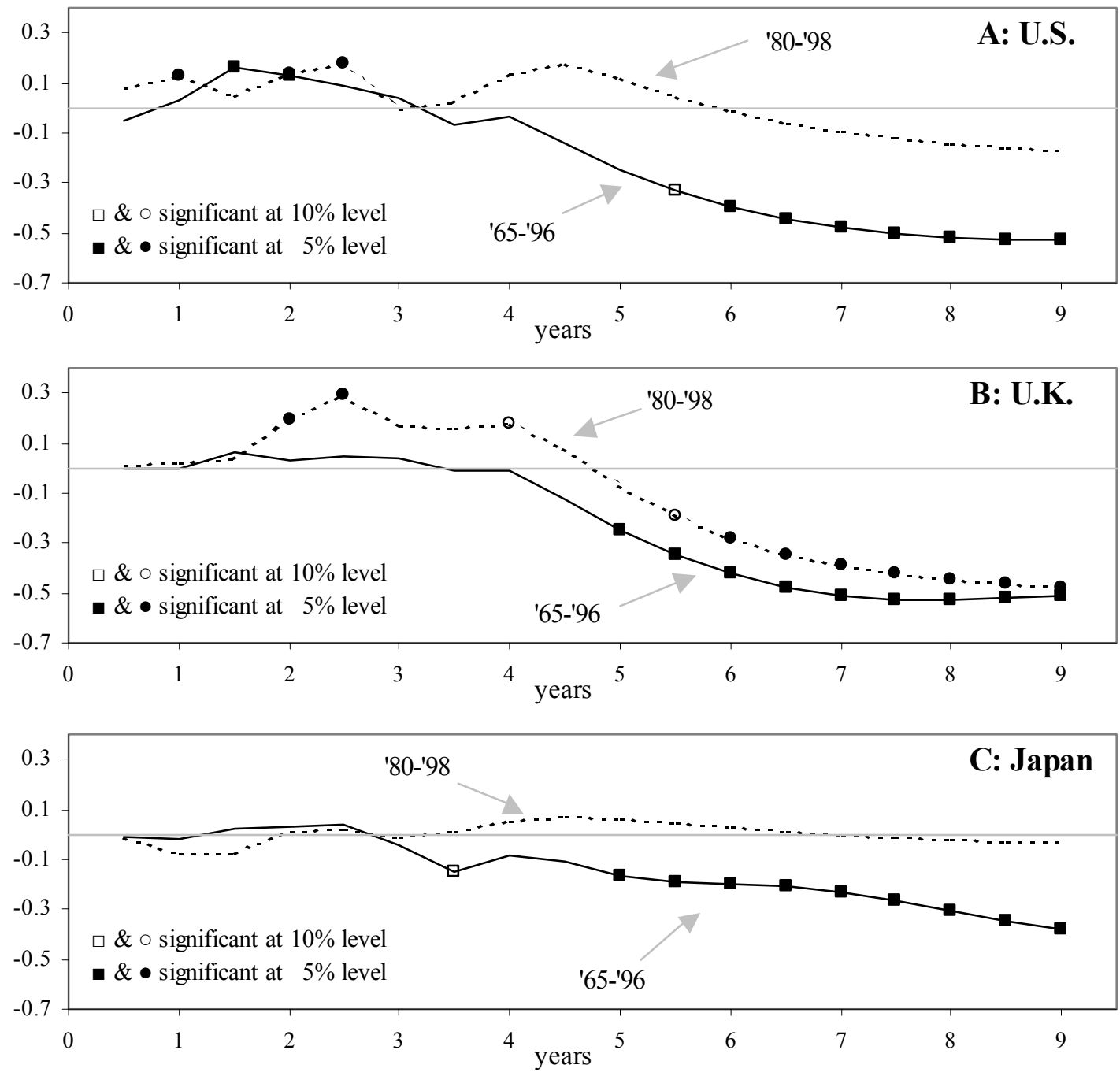

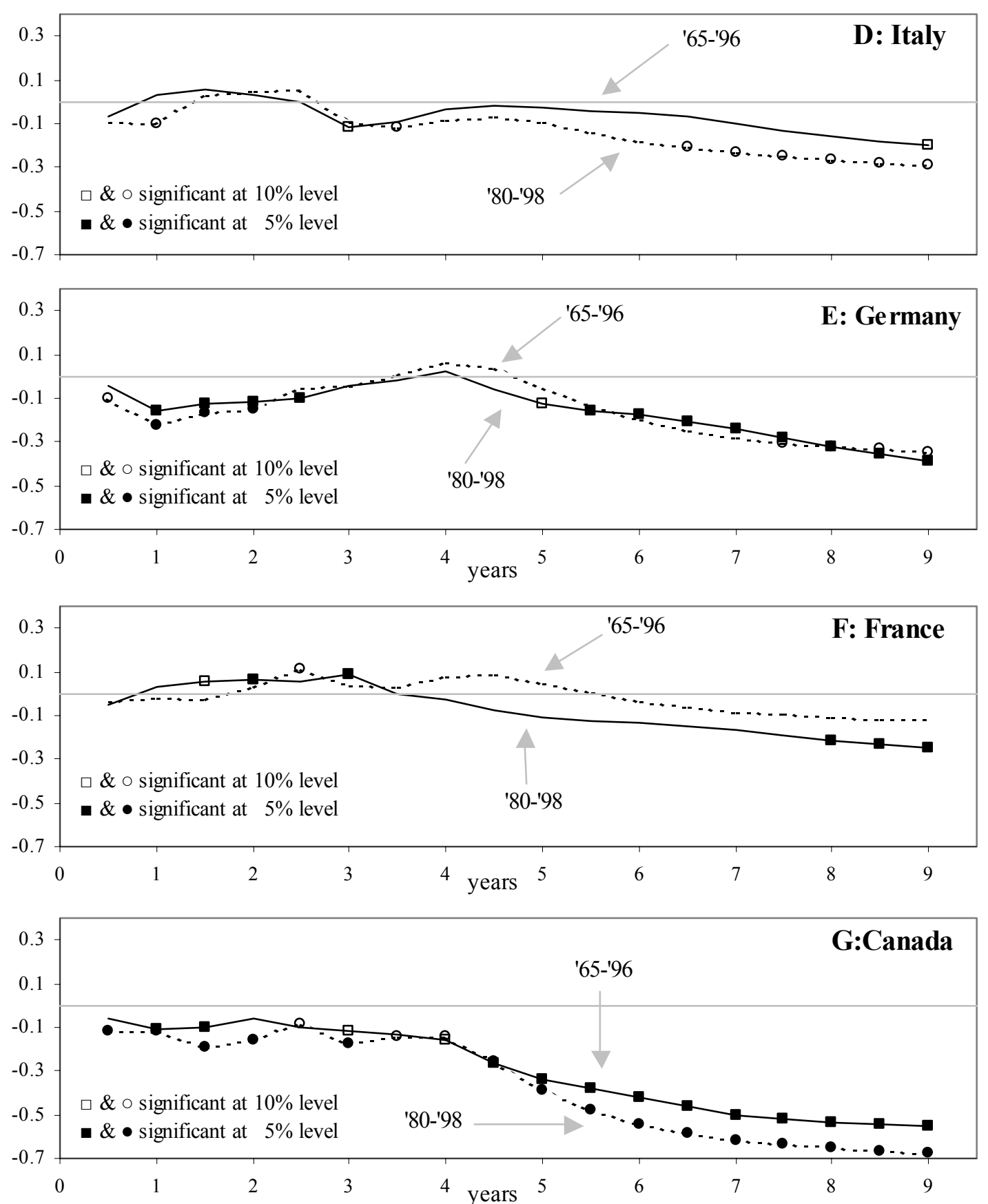

Note: These panels plot the correlation coefficients of the filtered monthly CPI and industrial production. The trend is calculated using a two-sided filter that extends the indicated sample by five years for the full sample and by three years for the shorter sample. Standard errors are calculated with the VARHAC procedure of Den Haan and Levin (1997).

We find results that resemble those found in Section 3. That is, correlation coefficients typically turn negative when the truncation frequency of the high-pass filter decreases, which means that the residual includes more of the original series associated with cycles having a longer period. For the full sample we find significant negative 
correlation coefficients for 6 countries, although for one of those countries, Italy, only one negative correlation coefficient is significant. Again there is some evidence of positive short-run correlation. When we look at the results for the recent sample, then we see that, as in Section 3, the correlation coefficients for Japan change substantially and the coefficients for the U.S. increase and even become positive for truncation periods between four and five years.

\subsection{High-pass filters and quarterly data}

Figure 5 plots the correlation between the filtered quarterly GDP and its deflator. As in Section 3, there is less evidence of positive correlation when GDP and its deflator are used than when the consumer price index and industrial production are used. As in Section 4.2, we observe that U.S. correlation coefficients are substantially higher during the more recent sample.

Figure 5: Correlation coefficients of filtered quarterly data
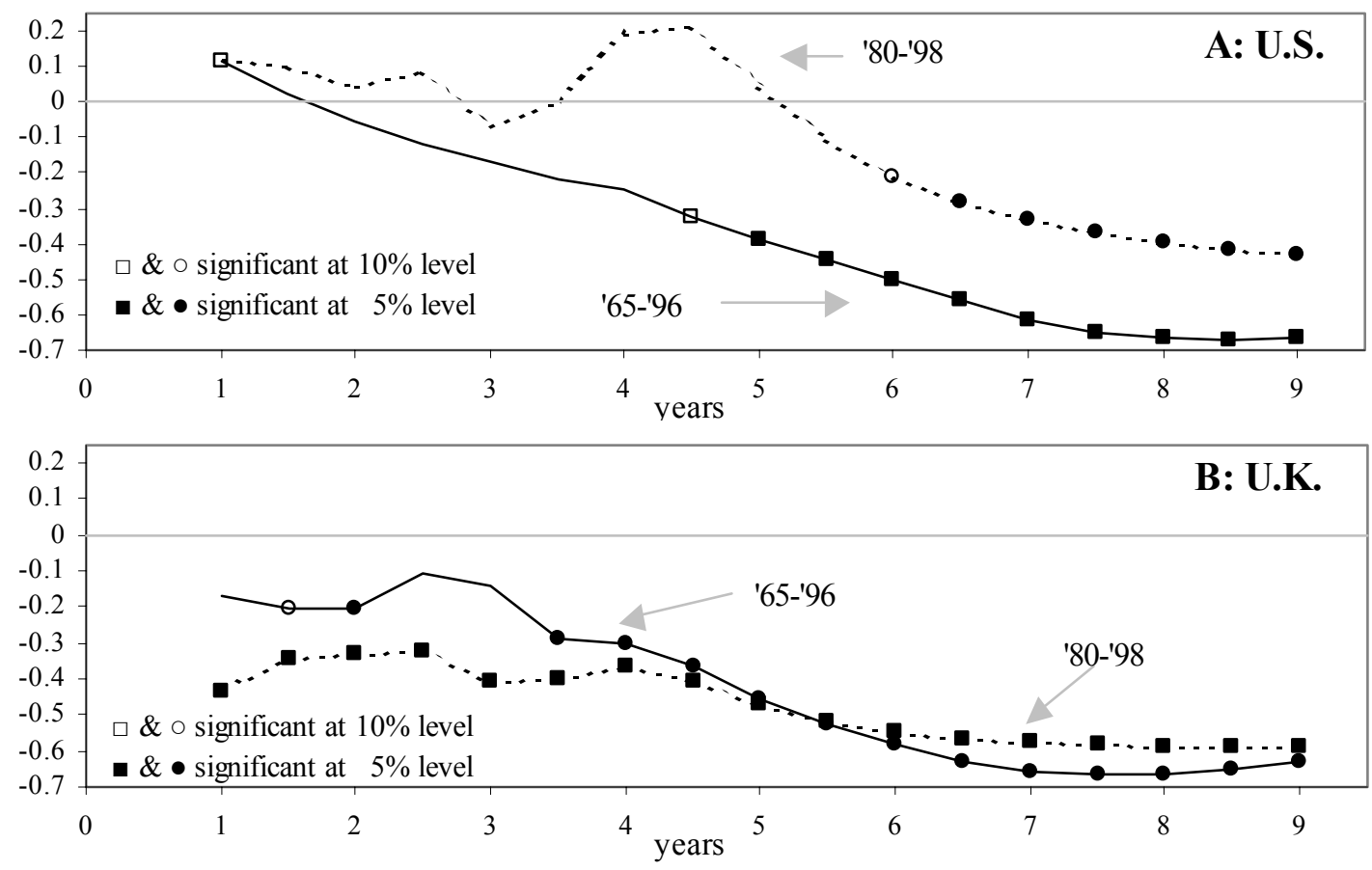

Note: These panels plot the correlation coefficients of the filtered quarterly GDP and its deflator. The trend is calculated using a two-sided filter that extends the indicated sample by five years for the full sample and by three years for the shorter sample. Standard errors are calculated using the VARHAC procedure of Den Haan and Levin (1997). 


\section{Comparison of different comovement measures}

This paper shows that using a rich set of statistics that captures the dynamic features of the data makes it possible to bring to light characteristics of the data that simpler procedures cannot. In particular, in contrast to the established procedures both the VAR methodology of Section 3 and the frequency-domain filters of Section 4 directly, and in an intuitive manner, reveal that in several samples the relationship between prices and output is characterized by a positive as well as a negative comovement.

The idea of descriptive statistics is that they summarize key features of the data in an efficient manner. Different (comovement) statistics obviously capture different aspects of a set of time series. In this paper this occurred when we compare the two different sample periods. In particular, with the VAR method we find that correlation coefficients are substantially more negative for the sample consisting of only the last two decades for five of the nine cases considered in Figures 1 and 2. In contrast, with the frequency filters we do not observe such a decrease in any of the nine cases.

The question arises what can explain these differences. Productivity increases because of technological inventions clearly have been important during the last two decades. Arguably, a decrease in regulations and other market distortions may have increased productivity as well. The productivity increases have been credited for increasing output and keeping inflation low. If these changes in productivity are persistent it may very well be that the price and output movements associated with these productivity changes are captured by the VAR forecast errors but correspond to low frequency movements that are not captured by the high-pass filters considered.

\section{Appendix: Data sources}

The data used were downloaded from $\underline{h t t p: / / w w w . s o u r c e o e c d . c o m ~ o n ~ M a y ~} 8^{\text {th }} 2002 .{ }^{10}$ We also made the data available at http://weber.ucsd.edu/ wdenhaan.

For Canada we used "Real GDP: industry ISIC C-E sa - proxy" and for all other countries we used "industrial production ISIC C-E sa". For all countries we used "CPI all units" as the monthly consumer price index. For both the U.S. and the U.K. we used "Gross Domestic Product 1996 prices sa" as the quarterly real activity measure and we used the ratio of "Gross Domestic Product current prices sa" and "Gross Domestic Product 1996 prices sa" as the quarterly price measure.

\footnotetext{
${ }^{10}$ The CPI data for Japan is from the International Monetary Fund's International and Financial Statistics.
} 


\section{References}

Ball, L., and N.G. Mankiw, 1994, A sticky-price manifesto, Carnegie-Rochester Conference Series on Public Policy 41, pp. 127-151.

Baxter, M., and R.G. King, 1999, Measuring business cycles: Approximate band-pass filters for economic time series, Review of Economics and Statistics 81, pp. 575593.

Canova, F., and G. de Nicoló, 1999, On the sources of business cycles in the G-7, manuscript, Universitat Pompeu Fabra.

Chadha, B., and E. Prasad, 1993, Interpreting the cyclical behavior of prices, IMF Staff Papers 40, pp. 266-298.

Cogley, T., and J.M. Nason, 1995, Effects of the Hodrick-Prescott filter on trend and difference stationary time series implications for business cycle research, Journal of Economic Dynamics and Control 19, pp. 253-278.

Cooley, T.F., and L.E. Ohanian, 1991, The cyclical behavior of prices, Journal of Monetary Economics 28, pp. 25-60.

Den Haan, W.J., 2000, The comovement between output and prices, Journal of Monetary Economics 46, pp. 3-30.

Den Haan, W.J., and A.T. Levin, 1997, Practioner's guide to robust covariance matrix estimation, in Handbook of Statistics 15, G.S. Maddala and C.R. Rao, eds., Elsevier (Amsterdam), pp. 299-342.

Den Haan, W.J., and S. Sumner, 2001, The comovements between real activity and prices in the G7, CEPR discussion paper \#2801.

Hamilton, J.D., 1994, Time Series Analysis, Princeton University Press.

Hansen, L.P., and J.J. Heckman, 1996, The empirical foundations of calibration, Journal of Economic Perspectives 10, pp. 87-104.

Hodrick, R.J., and E.C. Prescott, 1997, Postwar US business cycles: An empirical investigation, Journal of Money, Credit and Banking 29, pp. 1-16.

Judd, J.P., and B. Trehan, 1995, The cyclical behavior of prices: Interpreting the evidence, Journal of Money, Credit, and Banking 27, pp. 789-797.

Ravn, M.O., and M. Sola, 1995, Stylized facts and regime changes: Are prices procyclical?, Journal of Monetary Economics 36, pp. 497-526.

Ravn, M.O. and H. Uhlig, 2002, On adjusting the HP-filter for the frequency of observations, Review of Economcis and Statistics 84, pp. 371-376. 